\title{
PREDATOR CONTROL AND PREDATOR-PREY RELATIONSHIPS
}

\author{
By Ira N. Gabmielson \\ President, Wildlife Management Institute
}

In the last twenty years, many careful studies of predation and predator-prey relationships have been carried on by the U.S. Fish and Wildlife Service, by various state conservation departments, and by private individuals and universities. Many of these studies have been carefully planned to work with as many factors as possible under control. In many of them, control areas were established for comparative purposes. As a result, there is a growing mass of information on predation based on something more than opinion or conclusions drawn from isolated observations.

It might be stated that $\Omega$ distinction is often made between predator control to protect domestic stock and poultry and predator control to benefit other wild species of birds or mammals. Many students recognize the economic problem involved in predation upon poultry and livestock. This involves the question of a livelihood which sometimes depends upon a thin margin of profit in the operation. Comparatively small losses of livestock or poultry ean, under such circumstances, mean the difference between a profit or the failure to make one. There are many problems in connection with this type of predator control, but these considerations do not dircetly apply to predator-prey relntionships.

In general, the various studies strongly tend to show that predation normally affects individuals that are surplus, in the sense that they are in excess of the carrying capacity of their home range during the most unfavourable seasons. Many American biologists believe that if the predators, or hunters, did not take these individuals, they would die from other causes. They often draw the corollary conclusion that normal predation has little influence upon the succeeding year's crop of game birds, mammals, or fish.

'The numerous controlled experiments bear this out; experiments in which similar areas as near alike in terrain, topography, food and cover as could be selected have been used as controls. On one area the predators are climinated as far as possible; on the check arca, no predator control is carried out. Careful checks are made of game bird populations on each arca both prior to the predator control and before and after the hunting 
season. In general, these studies have shown that it is possible to harvest by hunting about as many birds from the intensive predator control area as are taken from the area without predator control. In some cases, a greater crop was harvested from the predator control units than from those in' which no control was practised.

This has been repeated in widely different ecological zones. The investigators usually have come about to the same conclusion-that predation is not a vital factor in the survival of sufficient seed stock to produce a crop in the following year.

There are fairly well authenticated cases in which a predator control effort has been accompanied by a dramatic increase in a prey species. There is considerable evidence to indicate that this has in some cases been a cause-and-effect relationship. For every one of these instances, however, there are many in which an intensive predator control programme produced no measurable change in the abundance of the prey species.

Most biologists in this country bclieve that food shortage, lack of adequate cover, or of food and cover in the right relationship, or unseasonable weather at critical times of the year arc much more important factors in limiting populations of game birds or mammals than predation. In other words, they do not give it the importance that the average gunner does whenever he happens to see an actual case of predation.

Perhaps the most intensive study of predator-prey relationships yet made here was that carricd on by Frank and John Craighead and just published under the title of "Irwks, Owls, and Wildlife" ('The Stackpole Company, ITarrisburg, Pennsylvania). These men studied the population inter-relationships of hawks and owls and their prey species on arcas of land that could be carefully checked and censused at regular intervals. 'Their studies give an indication of the complicated mechanism involved in predator-prey relationships and are too involved to summarize in a short article.

The present considerable information tends to indicate that while predation alone cannot prevent periodic upswings in numbers of prey species, the lack of sufficient predator pressure can be one of the reasons for such upswings. 'The Craighend brothers believe that predators exercise a rather steady pressure on common prey species, and that the winged predators are especially effective because they can quickly concentrate their numbers (outside of nesting sensons) in areas where high densities of acceptable prey exist. Their studies revenl concentrations of wintering hawks and owls on areas harbouring big populations of 
meadow micc and other small rodents, and a considerable decrease in the number of wintering birds in years of low density of small rodent populations.

This study has been too recently published to permit other biologists to analyse it thoroughly, but it gives one of the best pictures yet presented of the rather complicated mechanism by which predation operates as a biological force.

Throughout the book there is some indication that predator control is desirable from a human standpoint where valuable species have low populations, but that any control should be based upon the actual conditions in the area on which control is proposed. This study, which involved game species only incidentally, concerned itself with the prey species that were abundant enough to enter in significant numbers into the food of the hawks and owls.

It should be understood that in the United States there are few operations approaching the intensity of game stocking and attempts to build up huge populations of game birds on limited areas, such as has been practised in England. There are relatively few privately owned units in the United States that attempt anything similar to this practice. Wildlife management is a function of the state or the federal governments, with the states carrying much the larger part of the work, and the methods of managing game must be extensive rather than intensive. Under such conditions, the major wildlife management efforts are to build up and maintain as big a supply of usable game as can be produced naturally upon the available land area.

Artificial propagation and distribution of game birds is, in many states, a relatively small supplementary tool. It is used where needed in the more progressive states; and somewhat as a sop to the gunners in the states where little effort is made to do anything except put on a show for the sportsmen. Under $\Lambda$ merican conditions, small upland game species are fairly widely dispersed, and it is seldom possible to sec the number of pheasants, for example, in a given area that one can sce on some of the great estates in England. The same is true of native species.

Biologists generally regard predator control as a management device which can be used effectively when predation happens to be the factor that is holding down game populations, but that general predation suppression campaigns under our conditions are a waste of time and effort when applied to wide areas in an effort to build up populations of game birds, mammals, or fish. Many biologists who have worked with this problem believe 
that there are exceptions to this rule, and nearly all of them have had some experience in finding areas in which a reduction of predators was followed by a build-up of the prey species. There is, therefore, an effort to use this tool more accurately where it is needed, although one must admit that public sentiment has not kept pace with the understanding among the biologists.

Predator campaigns are still very popular with many gunners and many bounties are still paid by various states, although bounties generally are on the way out. The number of states paying bounties is decreasing slowly, and even in states where some bounties are still in effect, not as many species as formerly are included in bounty laws. This is occurring not for sentimental reasons but because it is a growing conviction that money expended on general predator campaigns is a waste of funds that might better be used for some other purpose. 